\title{
Comparative study of diesel sorption performance between Chorisia speciosa fibers and a commercial polyurethane foam
}

\author{
Carla Gonçalves Albuquerque ${ }^{1}$, Lucas Meili ${ }^{2}$, João Inácio Soletti ${ }^{1}$, \\ Leonardo Mendonça Tenório de Magalhães Oliveira ${ }^{2}$, Jaly Márcio Espíndola Filho ${ }^{1}$, \\ Aderjane Ferreira Lacerda ${ }^{3}$, Reimar de Oliveira Lourenço ${ }^{3}$
}

\footnotetext{
${ }^{1}$ LASSOP - Universidade Federal de Alagoas, Laboratório de Sistemas de Separação e Otimização de Processos, Av. Lourival Melo Mota, s/n, CEP: 57072-900, Maceió, Alagoas, Brazil.

${ }^{2}$ LAPRO - Universidade Federal de Alagoas. Laboratório de Processos, Av. Lourival Melo Mota, s/n, CEP: 57072-900, Maceió, Alagoas, Brazil.

${ }^{3}$ DEQUI - Universidade Federal de São João del-Rei. Departamento de Engenharia Química, Rodovia MG-443, km 07, CEP: 36420-000, Ouro Branco, Minas Gerais, Brazil.

e-mail: leonardo.oliveira@ctec.ufal.br
}

\begin{abstract}
The objective of this work was to evaluate and compare the potential of polyurethane and kapok (Chorisia speciosa) residues as sorbent materials in the treatment of diesel spillage. To determine the sorption capacity, gravimetric tests were performed in static medium at room temperature and at different temperatures $(10,15$ and $28{ }^{\circ} \mathrm{C}$ ) and varying the time of contact between the sorbent material and diesel. It was observed that the sorption process occurs at a high velocity, with saturation point achieved in the first 5 minutes of contact, and the natural fiber presents higher sorption capacity compared to the polyurethane residue due to the low viscosity of diesel oil, that contributes to reduce de entrapment inside the porous foam. It has also been observed that the polyurethane residue exhibits an increase in sorption capacity with time and temperature increase. Scanning electron microscopy (SEM) analysis have shown that the main morphological property involved in smooth oil sorption was the high porosity associated with a small porous diameter. The kapok presented sorption capacity of $37 \mathrm{~g} / \mathrm{g}$ in equilibrium demonstrating its great potential of application as a sorbent material for the treatment of diesel spillage.
\end{abstract}

Keywords: Removal; Diesel; Natural Fiber; Polymer; Sorption.

\section{INTRODUCTION}

Every year, an average of 5 million tons of oil is transported by sea around the world and the impact of oil spill on the ecosystem is severe and cannot be underestimated. Several factors can influence in choosing the appropriate strategy control to face oil spills and the main methods for spill cleanup are categorized into three main groups: physical methods including adsorbents, booms and skimmers, chemical methods, highlighting the use of chemical dispersants and burning in situ, and finally biological methods which include bioremediation [1-3].

The most common method of containment is the use of barriers containing polymeric sorbent materials with characteristics of high mechanical strength and adequate physicochemical properties [1], such as polyurethanes [4, 5], polypropylene fibers [6] and polyamide, which despite that high cost of production and nonbiodegradability, has been widely used in the remediation of oil spill scenarios due to their high oil holding capacity, which can be higher than 70 times the material's own weight [5-7].

Thus, the search for efficient, low-cost, low-energy, renewable energy treatments [8, 2, 9] or based on recycling methods [10-12] make sorbents a promising alternative in the reduction of oily contaminants and in elimination of a problematic environmental liability (in case of recycling of polymers) present at the current time [6].

Among the natural sorbents, kapok fiber, an agricultural product derived from the fruits of silk-cotton tree 
[13], has gained prominence due to its good water repellency and high oleophilicity owing to its cellulose based composition, hollow structure and a layer of waxy on its surface, making it a potential pollution control agent $[14,15]$.

Various researchers have been published works aiming to attest the high sorption potential of kapok fiber for oils as LIM and HUANG [16], $36 \mathrm{~g} / \mathrm{g}$, ABDULLAH, RAHMAH and MAN [17], $36.7 \mathrm{~g} / \mathrm{g}$, KARTINA and NOR SUHAILA [18], $30 \mathrm{~g} / \mathrm{g}$, ABEJERO et al. [19], $22.9 \mathrm{~g} / \mathrm{g}$, DONG et al. [20], 12.53, indicating an approximate sorptive capacity between 12 and $40 \mathrm{~g}$ of oil / $\mathrm{g}$ of fibers.

Other authors, more recently, directed their interest to improve absorption and adsorption potential of these fibers. Wang, WANG and WANG [21] manufactured superhydrophobic and superoleophilic kapok fibers from a hydrothermal reaction method, by deposition of $\mathrm{ZnO}$ nano needles on the fiber surface and subsequent hydrophobic modification with dodecanetiol obtaining sorption levels between 40 and $70 \mathrm{~g} / \mathrm{g}$. Thilagvathi, Karan, Das [22] reported having the development of several fibrous composites based on the binary and tertiary mixture of kapok, cotton, milkweed and polypropylene fibers using thermal bonding to obtaining sorption capacities of $40.16 \mathrm{~g} / \mathrm{g}$ for a heavy oil and $23.0 \mathrm{~g} / \mathrm{g}$ for diesel oil. Tigno, Herrera, BALELA [23], manufactured a superhydrophobic material coating kapok fibers with $\mathrm{TiO}_{2}$ nanpaticles via hydrothermal method, and treating with solvent to improve its oleophilicity. The researchers evalated the sorptive capacity of this composite in four different oils, obtaining a maximum sorption of $44.78 \mathrm{~g} / \mathrm{g}$ for diesel.

The standards ASTM F716-09 and ASTM F726-12 are the indicated methods for sorbents performance evaluation as capacity testing. However, most researchers do not use the procedures proposed by ASTM when reporting their findings. Currently, most published studies with oil sorbents do not use some uniform pattern [3]. According to ASTM F726-12, the sorbent sample should be in contact with the sorbed material for 15 minutes and be subjected to a drip time of 15 seconds or 2 minutes (depending on the viscous nature of the sorbate).

However, BAZARGAN et al. [3] reported that the indicated time may be insufficient for a total dripping, depending on the sorbent material characteristics, thus specifying that the drip time will be a function of the type of sample and fluid analyzed. Thus, several authors have applied different times (contact and dripping) according on the type of sorbate and sorbent considered, since 5 to 60 minutes for contact time, until 10 seconds to 15 minutes for dripping $[24,8,15]$.

In this context, the general objective of this work was to evaluate the sorption capacity (S) to diesel oil in a static system using as sorbent material a synthetic compound, polyurethane foam, which is a fairly common solid residue, and a natural material of vegetable origin, kapok fibers (Chorisia speciosa), comparing both the sorbates used and assessing the kapok sorptive potential against one of the most widely used synthetic sorbent media, currently used in the global industry.

\section{MATERIALS AND METHODS}

\subsection{Materials}

The solid waste of polyurethane foams was obtained from refrigeration system discards found in the vicinity of Federal University of Alagoas (Alagoas - Brazil) and characterized primarily in density using a caliper and digital analytical balance. After four tests it was found that the average foam density recorded was $20.39 \pm 0.78$. The kapok was obtained from trees located in the Farol district of Maceio City (Alagoas - Brazil). In order to perform the sorption tests, it was decided to work with polyurethane foam samples in a circular format and kapok in spherical shape because this geometry facilitates the dripping process for both sorbents. Thus, polyurethane foam was cut longitudinally about $1.0 \mathrm{~cm}$ thick and in discs shape with average diameter of 3.5 $\mathrm{cm}$, and the kapok fibers were manually separated from their husks and seeds, cleaned and then rubbed to form a sphere. Soon after, they samples were weighed to establish a standard (mass between 0.1 and $0.15 \mathrm{~g}$ ).

The kapok fiber and polyurethane foam samples were characterized in scanning electron microscopy (SEM) to determine the morphologic aspects that would explain the diffusive behavior when in contact with diesel oil. The diesel oil used in the sorption experiments was a commercial S500 type purchased at a PETROBRAS fuel station in the city of Maceio (Alagoas - Brazil) and characterized in density using a digital densimeter and viscosity by a capillary viscosimeter at all studied temperatures. Both oil characterizations were performed in duplicates.

\subsection{Sorption capacity at room temperature}

The samples were dipped in a beaker containing $50 \mathrm{~mL}$ of diesel oil and left in contact with the liquid at predetermined times of 5, 10, 15, 20, 25 and 30 minutes. After the contact time, the samples were suspended and 
drained for 10 minutes at room temperature of $25^{\circ} \mathrm{C}\left( \pm 1^{\circ} \mathrm{C}\right)$ and then weighed on analytical balance.

\subsection{Sorption capacity at variable temperatures}

A thermostatic bath was used to change the medium temperature where a beaker containing $50 \mathrm{~mL}$ of diesel oil was applied. Samples were immersed and left in contact with the liquid at three predetermined times $(5,15,30$ $\mathrm{min})$ under three preselected temperatures $\left(10,15\right.$ e $\left.28^{\circ} \mathrm{C}\right)$. These temperatures were chosen to simulate a sorption behavior in marine spill scenarios, where for the Brazilian coast there is a variation of warm waters (close to $25^{\circ} \mathrm{C}$ ) and cold waters (between 16 and $8{ }^{\circ} \mathrm{C}$ ). After the contact time, the samples were suspended, drained for 10 minutes and weighed on analytical balance.

\subsection{Calculation of sorption capacity}

The sorption of a given component may be represented by the total mass of the liquid sorbed by the material matrix in relation to the mass of the dry material as represented by Equation 1. The determination of this parameter according to Equation 1 has been already used to analyze the affinity of the material by the components and swelling capacity of polymer membranes, aiding in the study of its influence on the selectivity of evaporation process [25].

$S=\left(W-W_{o}\right) / W_{o}$

Where, $S=$ Sorption capacity $(\mathrm{g} / \mathrm{g}), W o=$ dry sorbent mass $(\mathrm{g})$ and $W=$ swollen sorbent mass $(\mathrm{g})$.

\section{RESULTS}

\subsection{Kapok fiber and polyurethane foam characterization}

Figure 1 shows the SEM micrographs referring to the polyurethane and kapok fibers.
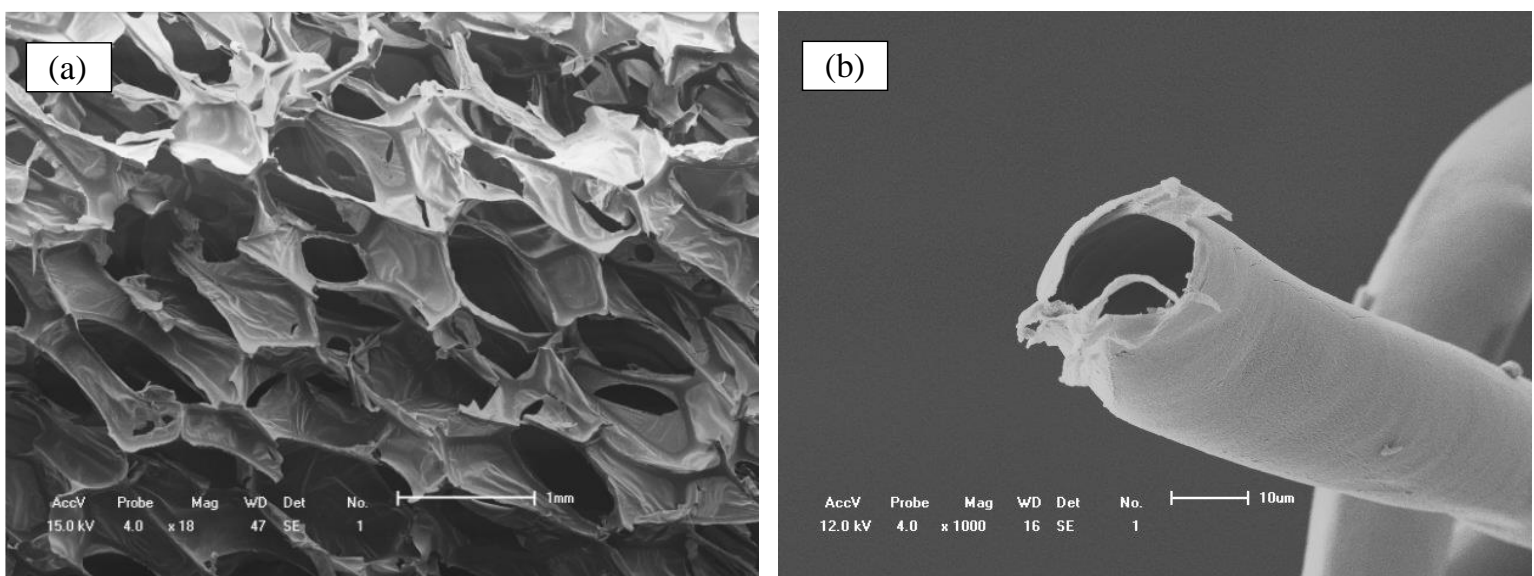

Figure 1: (a) Polyurethane foam and (b) kapok fiber SEM micrograph.

According to Figure 1 (a) it would be seen that polyurethane foam presents a high porosity surface, with cavities showing a diameter close to $1 \mathrm{~mm}$, which facilitates the sorbate penetration in its bulk. On the other hand, these large cavities when associated to sorption process of a low viscosity fluid may appear as interfering characteristic to sorbent, since sorbate would be more prone to escape from the internal structure of the material.

At Figure 1 (b), it can be observed that kapok fibers are a tubular cylindrical structures with smooth surface morphology that presents an inner lumen that gives them high porosity and, because its small pore diameter - a few micrometers, it is suggested that the material has a high sorbate retention capacity, even when the sorbed fluid has a low viscosity.

\subsection{Diesel characterization}

Table 1 shows the viscosity characterization for diesel, the sorbate fluid. Also, the measured diesel density was 
$0.8249 \pm 0.054 \mathrm{~g} / \mathrm{cm}^{3}$ at $26.5{ }^{\circ} \mathrm{C}$. This result shows that diesel oil is a light and smooth fluid, attesting the contact time in no more than 30 minutes at sorption test until its saturation point, according the KUMPANENKO et al. [26] research.

Table 1: Diesel viscosity analysis at different temperatures.

\begin{tabular}{c|c|c|c}
\hline TEMPERATURE (ㅇ) & TIME FLOW (s) & KINEMATICS VISCOSITY (cSt) & STANDARD DEVIATION \\
\hline 10 & 82 & 7.30 & 0.31 \\
\hline 15 & 62 & 5.00 & 0.22 \\
\hline 25 & 48 & 4.27 & 0.26 \\
\hline 28 & 45 & 4.01 & 0.17 \\
\hline
\end{tabular}

\subsection{Sorption capacity at room temperature}

Table 2 presents the results obtained, after triplicate analysis, for the mean sorption capacity in static medium at room temperature ( $\mathrm{Tr}$ ). According to Table 2, the polyurethane foam showed a reduction in oil removal capacity as the contact time increased. In the kapok case, the behavior was oscillatory in relation to the contact time mainly for this aleatory fibrous character, but considering standard deviation, it can be inferred that the system reached equilibrium very quickly, that is, after 5 minutes of contact, maintaining this behavior until the final tested time.

In addition, a sorption capacity three times higher than that obtained by the polyurethane was observed. This result demonstrated the great application potential of the material studied as a treatment agent for the removal of oil spills. In addition, it was noted in the bench analyzes that kapok ceases its drip before the polyurethane foam.

BAZARGAN et al. [3] explains that immediately after removal of the adsorbent on the liquid, gravitational forces act on the system, causing the rapid large oil removal from the adsorbent. As more oil is lost and the drainage process keep working, the remaining oil from the adsorbent becomes less susceptible to droplets. The procedure continues until the gravity is not strong enough to remove all the excess of oil from the sorbent.

Table 2: Static sorption test at room temperature (Tr).

\begin{tabular}{c|c|c|c}
\hline SORBENT MATERIAL & CONTACT TIME $(\mathbf{m i n})$ & $\mathbf{S}(\mathbf{g} / \mathbf{g})$ - Average & STANDARD DEVIATION \\
\hline \multirow{4}{*}{ Polyurethane } & 5 & 11.76 & 0.34 \\
\cline { 2 - 4 } & 10 & 7.77 & 0.17 \\
\cline { 2 - 4 } & 15 & 8.14 & 0.93 \\
\cline { 2 - 4 } & 20 & 7.70 & 0.07 \\
\cline { 2 - 4 } & 25 & 9.27 & 0.25 \\
\cline { 2 - 4 } & 30 & 5.97 & 0.02 \\
\hline \multirow{5}{*}{ Kapok } & 5 & 37.14 & 6.31 \\
\cline { 2 - 4 } & 10 & 36.00 & 0.94 \\
\cline { 2 - 4 } & 15 & 37.20 & 0.33 \\
\cline { 2 - 4 } & 20 & 36.08 & 2.52 \\
\cline { 2 - 4 } & 25 & 35.88 & 4.97 \\
\cline { 2 - 4 } & 30 & 37.70 & 3.64 \\
\hline
\end{tabular}

This good sorption for kapok fibers would be explained mainly because of its composition. RIJAVEC [27] characterized the kapok and found that its structure is composed by cellulose (64\%), lignin (13\%) and polysaccharides $(23 \%)$, which provides good interaction with organic molecules, aided by the waxy wall on the surface maximizing the van der Waals forces. Furthermore, the lumen structure, that contributes with $77 \%$ of all fiber volume [28], confer an additional sorption only by filling these empty spaces [17].

It was also observed that the standard deviation for kapok analysis was higher than the polyurethane. It can be explained by random distribution of the natural fibers in each tested sample. Probable, some specific orientation favors more the sorption than others. 
Analyzing the Figure 2, generated from the data found in Table 1, we can observe the kinetics sorption curves for polyurethane and kapok and notice that the equilibrium point of the two materials probably occurred in the first 5 minutes, suggesting a quick sorption for both. For polyurethane, it was noted that there was a downward trend after this initial time. This behavior probably occurred due to experimental error, or even small differences (imperfections) in the size distribution of the porous volumes of the samples.

According to what is observed in Figure 2, it is possible to suggest that the sorption phenomenon would have occurred in two major stages: At first moment, oil was transported to the surface of sorbent through attractive interactions from the functionalities. Later, oil would have been transported to the bulk of the material and to isolated interactions sites. However, due to the high pore size of the sorbents, these steps occurred very quickly.

The low retention of polyurethane foam in relation to the kapok fibers can be explained according to the statements of [26] that found the sorption capacity of polyurethane depends substantially on the degree of cell opening, which is responsible for the permeability of material. According to the authors, light petroleum fractions such as gasoline and diesel oil saturate the sorbent in a short period of time (no more than 30 minutes), while heavier fractions of crude oil cause saturation at intervals longer than 50 minutes. The high porosity character of polyurethane foam was observed in SEM micrographs (Figure 1) and attested the literature explanation. In addition, it may also had occurred due to the lack of superficial interaction due to absence of functional oleophilic groups.

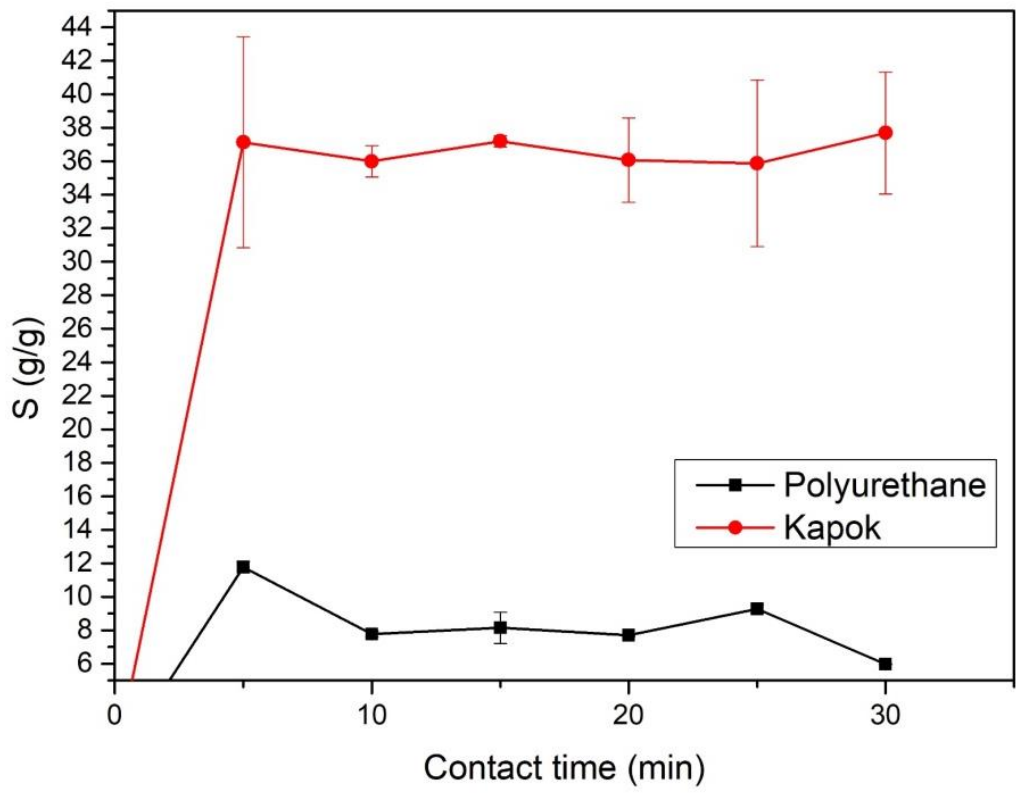

Figure 2: Kinectics of sorption by polyurethane foam $(\boldsymbol{\Lambda})$ and kapok fiber $(\bullet)$.

\subsection{Sorption capacity at variable temperatures}

The results of the dry sorption test at different temperatures are presented at Table 3. From Table 3, it can be seen that, unlike at higher temperatures (room temperature and $28^{\circ} \mathrm{C}$ ), prolongation of contact time had no significant influence in the removal capacity of polyurethane. Such results are similar as those found by DUONG and BURFORD [4], which verified that total sorption tends to grow until about $90 \%$ of total capacity of sorbent material in the first minutes, reaching your final equilibrium value in, at least, 30 minutes of contact.

Table 3: Static dry sorption capacity (S) at different temperatures (T) and contact times (t).

\begin{tabular}{|c|c|c|c|c|}
\hline SORBENT MATERIAL & $t(\min )$ & $\mathrm{T}\left({ }^{\circ} \mathrm{C}\right)$ & $S(g / g)$ - AVERAGE & STANDARD DEVIATION \\
\hline \multirow{5}{*}{ Polyurethane } & 5 & \multirow{3}{*}{10} & 10.27 & 2.49 \\
\hline & 15 & & 9.24 & 1.91 \\
\hline & 30 & & 10.73 & 2.32 \\
\hline & 5 & \multirow{2}{*}{15} & 7.30 & 0.70 \\
\hline & 15 & & 10.89 & 0.44 \\
\hline
\end{tabular}




\begin{tabular}{|c|c|c|c|c|}
\hline & 30 & & 9.41 & 0.44 \\
\hline & 5 & \multirow{3}{*}{28} & 9.25 & 0.18 \\
\hline & 15 & & 9.94 & 1.04 \\
\hline & 30 & & 8.74 & 0.09 \\
\hline \multirow{9}{*}{ Kapok } & 5 & \multirow{3}{*}{10} & 34.74 & 1.93 \\
\hline & 15 & & 35.15 & 1.68 \\
\hline & 30 & & 42.04 & 4.07 \\
\hline & 5 & & 29.76 & 4.30 \\
\hline & 15 & 15 & 34.95 & 2.62 \\
\hline & 30 & & 39.07 & 3.98 \\
\hline & 5 & & 32.34 & 0.24 \\
\hline & 15 & 28 & 38.30 & 4.40 \\
\hline & 30 & & 32.58 & 1.13 \\
\hline
\end{tabular}

Analyzing the sorption behavior in front of the system temperature variation, we observed some dependence for both materials. Figure 2 shows the mean values of sorption for polyurethane (a) and kapok (b) considering the influence of temperature treated in Table 3. It is possible highlight that polyurethane foam had significant influence of temperature on the five first minutes of contact, where at $10{ }^{\circ} \mathrm{C}$ was possible uptake $10.27 \mathrm{~g} / \mathrm{g}$ and at $15{ }^{\circ} \mathrm{C}$ was obtained only $7.30 \mathrm{~g} / \mathrm{g}$. However, at the same contact time, when temperature achieves $28{ }^{\circ} \mathrm{C}$ the sorption capacity has risen again until $9.25 \mathrm{~g} / \mathrm{g}$. After a transition period between 10 and 25 minutes of contact, near of equilibrium point, we obtained that low temperatures are more indicated for better results as long is the period of contact. For kapok fibers, the same initial behaviors were observed with rapid sorption, then a transition interval was observed between 10 and 25 minutes, until finish close to equilibrium with rise on the uptake capacity for $28^{\circ} \mathrm{C}$ when compared with $10^{\circ} \mathrm{C}$. At $15^{\circ} \mathrm{C}$, kapok fiber presented a growing shape, but in a lower rate as compared with the lowest studied temperature.

Thus, it was noted that with increase of temperature, there was a tendency of fall in sorption potential of the materials. This behavior was also observed in the literature, where, according to Ifelebuego and Momoh [29], who studied the sorption capacity of coconut residues with vegetable oil and diesel oil, this parameter decreased with increasing temperature. According SHAO et al. [30], this is due to the reduction of permeability that occours with materials when the temperature rises. This increase generates the dilatation of the sorbent medium and reduces the porous volume of the material, reducing the permeable channels and, consequently, the surface area of oil adsorption and absorption. Besides, [31] and [32] found that when temperature increases, the speed of Brownian motion will also increase, and the system requires more energy to adhere the oil molecule on the sorbent surface. In addition, the increase in temperature makes diesel less viscous, which leads, within the time of dripping, to a larger oil volume drained out of the sorbent material [25]. 

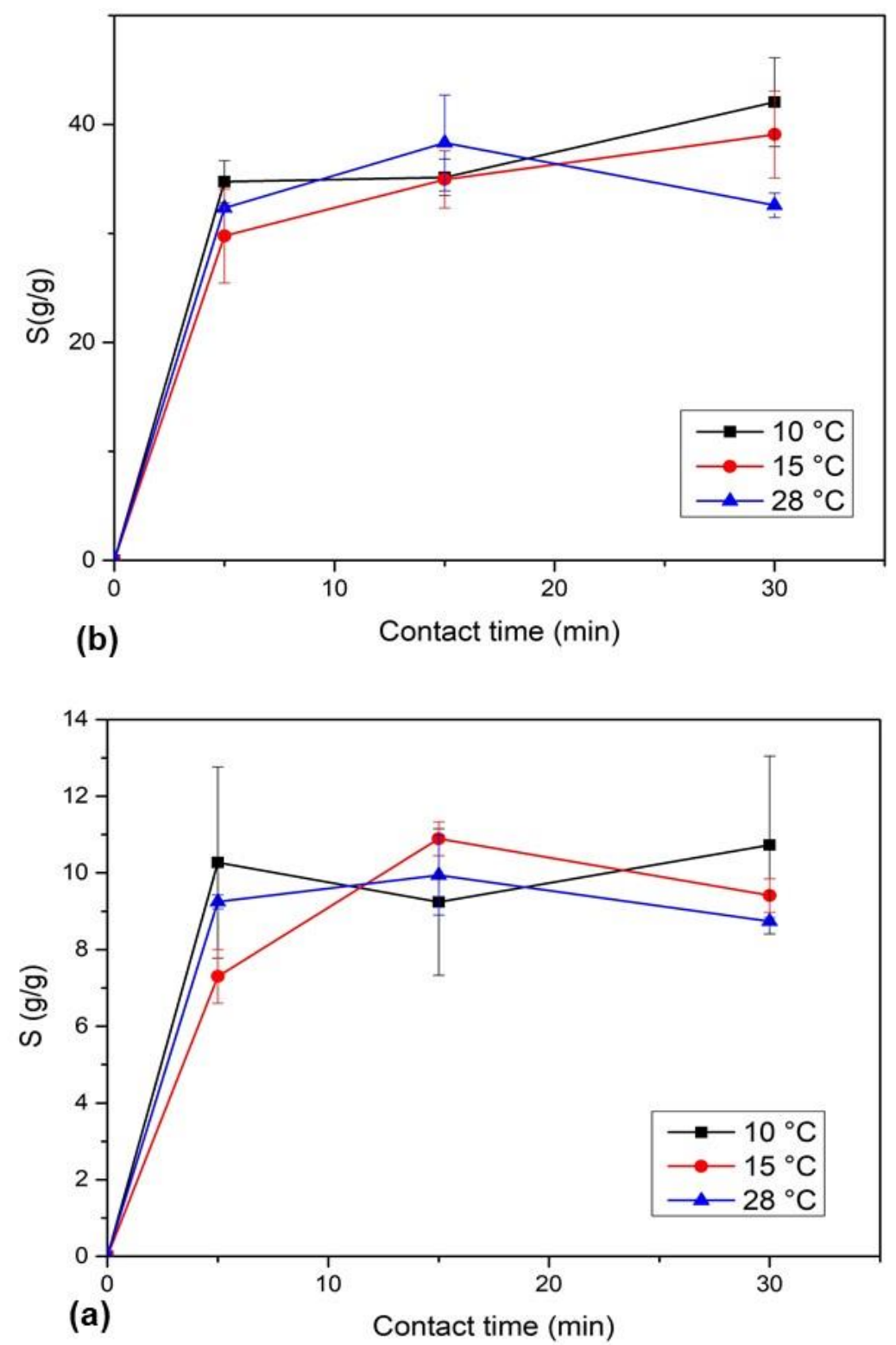

Figure 3: Polyurethane (a) and kapok (b) sorption capacity as function of contact time for each temperature.

\section{CONCLUSIONS}

Therefore, according to the present study, kapok has a higher sorption capacity of diesel oil when compared to polyurethane. However, the polymer foam presents a greater stability in his sucked volume by contact time. In static sorption test at room temperature, the highest sorption capacity recorded was $11.76 \mathrm{~g} / \mathrm{g}$ e $37.70 \mathrm{~g} / \mathrm{g}$ for polyurethane foam and kapok respectively. It was also observed that the established drainage time (10 minutes) was favorable to the gravimetric assays considering the type of fluid being sorbed. In static sorption with varied temperature $\left(10,15\right.$ e $\left.28^{\circ} \mathrm{C}\right)$, was observed that the highest recorded capacity occurred at $10{ }^{\circ} \mathrm{C}$ e 30 minutes of contact time, being $13.05 \mathrm{~g} / \mathrm{g}$ for polyurethane foam and $44.92 \mathrm{~g} / \mathrm{g}$ for kapok. From these observations, a promising potential of kapok can be noted as an agent to be applied as a sorbent medium in oil spill scenarios, since it had superior sorptive behavior when compared to a commercially known sorbent.

\section{ACKNOWLEDGMENTS}

The authors thank CAPES, CNPq, FAPEAL and UFAL for supporting.

\section{BIBLIOGRAPHY}


[1]. AL-MAJED, A.A., ADEBAYO, A.R., HOSSAIN, M.E. "A sustainable approach to controlling oil spills", Journal of Environmental Management, 113, pp. 213-227, 2012.

[2]. BAYAT, A., AGHAMIRI, S.F., MOHEB, A., et al."Oil spill cleanup from sea water by sorbent materials", Chemical Engineering and Technology, 28(12), pp. 1525-1528, 2005.

[3]. BAZARGAN, A., TAN, J., MCKAY, G. " Standardization of Oil Sorbent Performance Testing", Journal of Testing and Evaluation, 43(6), pp. 1-8, 2015.

[4]. DUONG, H.T.T., BURFORD, R.P. "Effect of foam density, oil viscosity, and temperature on oil sorption behavior of polyurethane", Journal of Applied Polymer Science, 99, v. 1, pp. 360-367, 2006.

[5]. PINTO, J., ATHANASSIOU, A., FRAGOULI, D. " Effect of the porous structure of polymer foams on the remediation of oil spills", Journal of Physics D: Applied Physics, 49, v.14,pp. 1-8, 2016.

[6]. KHAN, E., VIROJNAGUD, W., RATPUKDI, T. " Use of biomass sorbents for oil removal from gas station runoff", Chemosphere, 57, v. 7, pp. 681-689, 2004.

[7]. T. DONG, S. CAO, G. XU, Highly porous oil sorbent based on hollow fibers as the interceptor for oil on static and running water, J. Hazard. Mater. 305, https://doi.org/10.1016/j.jhazmat.2015.11.030. pp. 1-7, 2016.

[8]. ASADPOUR, R., SAPARI, N.B., ISA, M.H., et al. "Acetylation of oil palm empty fruit bunch fiber as an adsorbent for removal of crude oil", Environmental Science and Pollution Research, 23 v. 12, pp. 1-11, 2016.

[9]. PAULAUSKIENE, T., JUCIKE, I. "Aquatic oil spill cleanup using natural sorbents", Environmental Science and Pollution Research, 22(19), pp. 14874-14881, 2015.

[10]. ARAÚJO, M.J.F.; MULLINARI, D.R., ARAÚJO, M. V. F. " Sorption of diesel oil from reusing of pet bottles", Cadernos UniFOA, 29, pp. 21-31, 2015.

[11]. SALEEM, J., BAZARGAN, A., BARFORD, J., et al. "Application of strong porous polymer sheets for superior oil spill recovery", Chemical Engineering and Technology, 38, v. 3, pp. 482-488, 2015.

[12]. SALEEM, J., NING, C., BARFORD, J., et al. "Combating oil spill problem using plastic waste", Waste Management, 44, pp. 34-38, 2015.

[13]. WANG, J., ZHENG, Y., WANG, A. "Coated kapok fiber for removal of spilled oil", Marine Pollution Bulletin, 69, pp. 91-96, 2013.

[14]. DONG, T., WANG, F., XU, G. "Theoretical and experimental study on the oil sorption behavior of kapok assemblies", Industrial Crops and Products, 61, pp. 325-330, 2014.

[15]. X. ZHANG, C., WANG, W., CHAI, X. et al. Kapok fiber as a natural source for fabrication of oil absorbent, J. Chem. Technol. Biotechnol. 92. https://doi.org/10.1002/jctb.5155. pp.1613-1619. 2017.

[16]. LIM, T.T., HUANG, X. "Evaluation of hydrophobicity/oleophilicity of kapok and its performance in oily water filtration: Comparison of raw and solvent-treated fibers". Industrial Crops and Product, 26, pp. 125-134, 2007.

[17]. ABDULLAH, M.A., RAHMAH, A.U., MAN, Z.J. " Physicochemical and sorption characteristics of Malaysian Ceiba pentandra (L.) Gaertn. as a natural oil sorbent", Journal of Hazardous Materials, 177, v.1, pp. 683-691, 2010.

[18]. KARTINA, A.K.S., SUHAILA, M.H.N. "Oil sorption capacity of kapok fiber". In: CHUSER 2012 2012 IEEE Colloq. Humanit. Sci. Eng. Res., doi:10.1109/CHUSER.2012.6504439, pp. 876-878, 2012.

[19]. ABEJERO, A.L.D.J., ALCANTARA, A.J., TRINIDAD, L.C. et al. "Kapok (Ceiba pentandra (L.) Gaertn.) fibers packed in nylon nets as sorbent for diesel oil spill and its ex-situ bioremediation". Journal of Environmental Science Management, 16, pp. 72-83, 2013.

[20]. DONG, T., XU, G., WANG, F. "Oil spill cleanup by structured natural sorbents made from cattail fibers". Industrial Crops and Products, 76, pp. 25-33, 2015.

[21]. WANG, J., WANG, A., WANG, W. "Robustly superhydrophobic/superoleophilic kapok fiber with ZnO nanoneedles coating: Highly efficient separation of oil layer in water and capture of oil droplets in oil-inwater emulsions". Industrial Crops and Products, 108, pp. 303-311, 2017.

[22]. THILAGAVATHI, G., PRABA KARAN, C., DAS, D. "Oil sorption and retention capacities of thermally-bonded hybrid nonwovens prepared from cotton, kapok, milkweed and polypropylene fibers". Journal of Environmental Management, 219, pp. 340-349, 2018.

[23]. TIGNO, S.D.; HERRERA, M.U.; BALELA, M.D.L. "Hidrophobicity of functionalized TiO2-based 
kapok nanocomposite". Surface and Coatings Technology, 350, pp.857-862, 2018.

[24]. KUMAGAI, S., NOGUCHI, Y., KURIMOTO, Y., et al. "Oil adsorbent produced by the carbonization of rice husks", Waste Mangement, 27, v. 4, pp. 554-561, 2007.

[25]. ANNUNCIADO, T.R., SYDENSTRICKER, T.H.D., AMICO, S.C. "Experimental investigation of various vegetable fibers as sorbent materials for oil spills", Marine Pollution Bulletin, 50, v.11, pp. 13401346, 2005.

[26]. KUMPANENKO, I.V., ROSCHIN, A.V., IVANOVA, N.A., et al. "Application of sorbents to the collection of crude oil and refined products spills", Russian Journal of Physical Chemistry B, 9, pp. 295-299, 2015.

[27]. RIJAVEC, T."Kapok in technical textiles", Tekstile, 51, pp. 319-331, 2008.

[28]. FERREIRA, R.T. Sorção de petróleo por fibras vegetais. MSc Dissertation, Federal University of Rio Grande do Norte, Natal, 2009.

[29]. IFELEBUEGO, A.; MOMOH, Z. "An evaluation of the adsorptive properties of coconut husk for oil spill cleanup", In: Proceedings of the International Conference on Advances in Applied Science and Environmental Technology, Thailand, 2015.

[30]. SHAO, J., HU, Y., MENG, T., et al. "Effect of Temperature on Permeability and Mechanical Characteristics of Lignite", Advances in Materials Science and Engineering, 2, pp. 1-12, 2016.

[31]. SIMONOVIC, B.R., ARANDELOVIC, D., JOVANOVIC, M., et al. "Removal of mineral oil and wastewater pollutants using hard coal", Chemical Industry and Chemical Engineering Quarterly, 15, v. 2, pp. $57-62,2009$.

[32]. WAHI, R., CHUAH, L.A., CHOONG, T.S.Y. et al. "Oil removal from aqueous state by natural fibrous sorbent: An overview", Separation and Purification Technology, 113, pp. 51-63, 2013.

\section{ORCID}

Carla Gonçalves Albuquerque

Lucas Meili

João Inácio Soletti

Leonardo Mendonça Tenório de Magalhães Oliveira

Jaly Márcio Espíndola Filho

Aderjane Ferreira Lacerda

Reimar de Oliveira Lourenço https://orcid.org/0000-0001-5044-4740

https://orcid.org/0000-0002-0307-8204

https://orcid.org/0000-0002-7758-9939

https://orcid.org/0000-0002-5709-1375

https://orcid.org/0000-0001-6777-4586

https://orcid.org/ 0000-0003-3328-1702

https://orcid.org/0000-0002-8649-9994 